\title{
Adsorption kinetics of platinum group elements onto macromolecular organic matter in seawater
}

\author{
Kai Liu' ${ }^{1,2}, 3$, Xuelu Gao ${ }^{1,2 *}$, Qianguo Xing ${ }^{1}$, Fushan Chen ${ }^{4}$ \\ ${ }^{1}$ CAS Key Laboratory of Coastal Environmental Processes and Ecological Remediation, Yantai Institute of Coastal \\ Zone Research, Chinese Academy of Sciences, Yantai 264003, China \\ ${ }^{2}$ University of Chinese Academy of Sciences, Beijing 100049, China \\ ${ }^{3}$ Dongying Municipal Bureau of Marine Development and Fisheries, Dongying 257000, China \\ ${ }^{4}$ College of Marine Sciences and Bioengineering, Qingdao University of Science and Technology, Qingdao 266042, \\ China
}

Received 1 June 2018; accepted 3 September 2018

(C) Chinese Society for Oceanography and Springer-Verlag GmbH Germany, part of Springer Nature 2019

\begin{abstract}
Adsorption kinetics of the interaction between Pt, Pd and Rh (defined here as platinum group elements, PGEs) ions and macromolecular organic compounds (MOCs, $>10 \mathrm{kDa}$ ), including humic acid, carrageenan and bovine serum albumin, and different cutoff fractions of natural organic matter $(>1 \mathrm{kDa}$ and $>3 \mathrm{kDa})$ obtained from seawater using centrifugal ultrafiltration devices were investigated. For a given element, all the adsorption kinetics did not reach equilibrium except the interaction between Pt and $>1 \mathrm{kDa}$ cutoff, and between Pd and humic acid For all the tested MOCs, the adsorption kinetics could be divided into two stages, a rapid adsorption process in the first $8 \mathrm{~h}$ and the desorption stage after the first $8 \mathrm{~h}$ until the equilibrium. The change trend of partition coefficient $\left(\log _{10} K_{\mathrm{d}}\right)$ values with experiment time was consistent with that of the kinetic curves. However, in the interaction between PGE ions and natural dissolved organic matter (NDOM), an obvious difference in the change trends of $\log _{10} K_{\mathrm{d}}$ and kinetic curves was observed. It indicated that the partition behavior of PGE ions interacting with NDOM in seawater was a combined effect of different organic constituents. The adsorption and $\log _{10} K_{\mathrm{d}}$ of PGEs in the $>1 \mathrm{kDa}$ NDOM fraction were higher and more stable than those in the $>3 \mathrm{kDa}$ NDOM fraction. The results also indicated that the 1-3 kDa NDOM may dominate the interaction between PGEs ions and NDOM. Moreover, no kinetic model could perfectly simulate the adsorption process. It indicated that the colloidal struction and morphology of MOCs or NDOM in seawater might be inhomogeneous. Hence, the interaction between PGE ions and organic matter in seawater was a complicated process and needs further research.
\end{abstract}

Key words: adsorption, kinetics, platinum group elements, macromolecular organic compounds, natural organic matter, seawater

Citation: Liu Kai, Gao Xuelu, Xing Qianguo, Chen Fushan. 2019. Adsorption kinetics of platinum group elements onto macromolecular organic matter in seawater. Acta Oceanologica Sinica, 38(8): 8-16, doi: 10.1007/s13131-019-1433-3

\section{Introduction}

The concentrations of Pt, Pd and Rh, defined here as platinum group elements (PGEs), which are widely used in industry, have dramatically increased in the environment, especially with the introduction of automotive catalytic systems (Koek et al., 2010; Mudd, 2012; Pawlak et al., 2014). Current evidence has demonstrated that PGEs would migrate easily in the environment and their hazards might be enhanced with the presence of some other pollutants (Ravindra et al., 2004; Wiseman and Zereini, 2009; Reith et al., 2014; Sørensen et al., 2016; Zimmermann et al., 2017). Hence, to invsestigate the relationship between PGEs and the compounds present in the environment is important for the evaluation of the potential risks of these elements to ecosystem and human health. In light of the probable migration path (vehicle exhaust-soil-aquatic system), PGEs would enter the aquatic system ultimately (Pawlak et al., 2014; Clément et al., 2015; Ruchter and Sures, 2015; Suchá et al., 2016; Mitra and Sen., 2017). The dissolved organic matter (DOM) is ubiquitous and plays a critical role in natural quantic environments (Verdugo et al., 2004; He et al., 2016). It would influence the migration and transformation of PGEs on the molecule level (Guo and Santschi, 2007).

Due to the possible critical role, the interactions between the natural dissolved organic matter (NDOM) and PGEs in the aquatic system have attracted more and more attention. The humic substances (HS) such as humic acid, fluvic acid and some other constituents of NDOM could increase the solubility of Pt and Pd in the aquatic system because of the strong interactions of PGEs with S- and N-donors (Wood et al., 1994; Wood, 1996). In addition, PGEs could form various metal complexes with different fractions of HS (Sures and Zimmermann, 2007). Cobelo-García (2013) reported the time-dependent speciation of rhodium chlorides with and without the presence of humic substances in the model freshwater. About six types of complexes were formed during the reaction, and around $15 \mathrm{~d}$ were required for the equilibrium formation between Rh-organic complexes. It showed the

Foundation item: The National Natural Science Foundation of China under contract No. 41376083; the Strategic Priority Research Program of the Chinese Academy of Sciences under contract No. XDA23050303.

*Corresponding author, E-mail: xlgao@yic.ac.cn 
important role of HS on the migration of PGEs in the aquatic environment. However, most laboratories focus on the interactions of HS and PGEs in a controlled aquatic environment. For the natural seawater containing various DOM (Baker and Spencer, 2004; Guéguen et al., 2006), this information is much insufficient, even though it is a critical step for a better understanding of the environmental behaviors and risks of PGEs.

In this research, controlled kinetic experiments were conducted to investigate the fractionation of PGE ions in seawater with the presence of different types of macromolecular organic compounds (MOCs) and different molecular weight cutoffs of NDOM. Because the organic matter in seawater is complicate (Baker and Spencer, 2004; Guéguen et al., 2006; Para et al., 2010; Ilina et al., 2014), some model MOCs which represent the known substances of NDOM including humic acid (HA), acidic polysaccharides (APS) and proteins were used (Yang et al., 2013; Lin et al., 2015). In this study, we focused on the role of the chemical constituents of NDOM and MOCs in the fractionation of PGEs in seawater; the effects produced by living organisms were not taken into account.

\section{Materials and methods}

\subsection{Macromolecular organic matter, natural organic matter and seawater}

The MOCs selected in this work were HA, carrageenan (CAS Number 9000-07-1) as a representative of APS and bovine serum albumin (BSA) a representative of proteins (Yang et al., 2013; Lin et al., 2015), and the details are shown in Table 1. Two experimental conditions were designed in this research: (1) the ultraviolet irradiated natural seawater (UVSW) condition in which DOM was removed but inorganic matrix was present; (2) the natural seawater (NSW) condition in which both DOM and inorganic matrix were present (the concentration of the dissolved organic carbon, DOC, was $2.06 \mathrm{mg} / \mathrm{L}$ ). The condition (1) was used to investigate the effects of the types of MOCs, and the condition (2) was used to examine the effects of the molecular weights of NDOM. The NSW was taken from the North Yellow Sea $\left(37.768^{\circ} \mathrm{N}\right.$, $123.726^{\circ} \mathrm{E}$ ), filtered through a $0.2 \mu \mathrm{m}$ capsule filter (Opticap ${ }^{\circledR}$, EMD Millipore Corporation) and stored in a $4 \mathrm{~L}$ polypropylene bottle $\left(\right.$ Thermo ${ }^{\circledR}$ ) at $4^{\circ} \mathrm{C}$ before used (not exceed $48 \mathrm{~h}$ ). The UVSW was prepared by irradiating NSW under the ultraviolet light (500 $\mathrm{W}$ ) for over $48 \mathrm{~h}$; most active NDOM was removed and the concentration of DOC was less than $0.1 \mathrm{mg} / \mathrm{L}$. The mixed stock solution of $1000 \mathrm{mg} / \mathrm{L}$ of each element was prepared in $2 \% \mathrm{HNO}_{3}$ (Turner et al., 2006; Cobelo-García et al., 2008) by Pt, Pd and Rh standards (chloride form, and supplied by General Research Institute for Nonferrous Metals, China). The preparation of the adsorption experiments was conducted in a clean bench. All experimental wares were prepared following a strict cleaning process, washed with Decon ${ }^{\circledR} 90$ ( $2 \%$ in Q-water) firstly and soaked in $10 \%$ $\mathrm{HNO}_{3}$ for $48 \mathrm{~h}$, then, rinsed five times with ultrapure deionized water $\left(\mathrm{PALL}^{\circledR}\right)$ and dried in a clean bench.

Table 1. Details of the macromolecular organic matter used in the experiments

\begin{tabular}{llll}
\hline $\begin{array}{l}\text { Type of macromolecular } \\
\text { organic matter }\end{array}$ & Representative chemical composition & Molecular weight & \multicolumn{1}{c}{ Provider } \\
\hline $\begin{array}{l}\text { Humic acid (HA) } \\
\text { Protein }\end{array}$ & $\begin{array}{l}\text { humic acid sodium salt } \\
\text { bovine serum albumin (BSA) }\end{array}$ & $>10 \mathrm{kDa}$ & $\sim 66.54 \mathrm{kDa}$ \\
Acidic polysaccharide & $\begin{array}{l}\text { carrageenan (Sigma-Aldrich SKU } \\
\text { number C1867) }\end{array}$ & $>20 \mathrm{kDa}$ & $\begin{array}{l}\text { Shanghai Luoshen Biological } \\
\text { Technology Co. Ltd } \\
\text { Sigma-Aldrich China Inc. }\end{array}$ \\
\hline
\end{tabular}

The natural seawater used in this study was filtered beforehand with $0.2 \mu \mathrm{m}$ membrane, removing most microorganisms, viruses, and nanoparticles. Hence, the filtered seawater could mainly contain macromolecules, ion pairs, and hydrated ions (Guo and Santschi, 2007). Considering the purpose and the centrifugal ultrafiltration (CFU) devices used in this study, we defined natural organic matter to the colloidal phase ( $1 \mathrm{kDa}$ cutoff to $0.2 \mu \mathrm{m}$ NDOM fraction) and the dissolved phase ( $<1 \mathrm{kDa}$ NDOM fraction) (Guo and Santschi, 1997). The results of this study were the adsorption behaviors of PGE ions interacting with the colloidal fractions between $1 \mathrm{kDa}$ and $0.2 \mu \mathrm{m} \operatorname{NDOM}(>1 \mathrm{kDa}$ fraction) and between $3 \mathrm{kDa}$ and $0.2 \mu \mathrm{m}$ NDOM ( $>3 \mathrm{kDa}$ fraction) (Guo and Santschi, 2007). The $<1 \mathrm{kDa}$ NDOM was not taken into account because there was no effective method to separate organic matter with the molecular weight $<1 \mathrm{kDa}$ and inorganic ions (Guo and Santschi, 2007).

\subsection{Adsorption studies}

The adsorption experiments were operated in polypropylene (PP) Erlenmeyer flasks. PP wares were reported to have low surface adsorption of PGE ions (Cobelo-García et al., 2007). Figure 1 shows the schema of the adsorption process. A total of $196 \mathrm{~mL}$ of the UVSW was added into a $250 \mathrm{~mL}$ PP Erlenmeyer flask (VIT$\mathrm{LAB}^{\circledR}$ ) and then the MOCs were spiked. The final MOC concentrations were $2 \mathrm{mg} / \mathrm{L}$, which was close to the DOC concentration of the NSW, i.e., $2.06 \mathrm{mg} / \mathrm{L}$. Before the spiking of the PGEs, the solutions were stirred for 30-45 min to ensure the homogeneous distribution of MOCs in seawater (Yang et al., 2013). In order to make the adsorption of MOCs achieve saturation, $1.25 \mathrm{~mL}$ of PGE stock solution was added to make the concentration of each Pt, $\mathrm{Pd}$ and $\mathrm{Rh}$ ion achieve $4 \mathrm{mg} / \mathrm{L}$, i.e., $20.5 \mu \mathrm{mol} / \mathrm{L} \mathrm{Pt}, 37.6 \mu \mathrm{mol} / \mathrm{L}$ $\mathrm{Pd}$ and $38.9 \mu \mathrm{mol} / \mathrm{L} \mathrm{Rh}$. The $\mathrm{pH}$ of the solution was adjusted to $\sim 8.2$ by adding $\sim 2 \mathrm{~mL}$ non-complexing Tris- $\mathrm{HCl}$ buffer solution ( $\mathrm{pH} \sim 8.5$ ) to maintain it. The volume of the final working solution was $200 \mathrm{~mL}$. The experiment was conducted in a shaker in the dark and sampled at $1,3,6,8,16,24$ and $48 \mathrm{~h}$, respectively. The same experiment procedure was performed in NSW, but no MOCs were added. The samples gained in the experiments on the UVSW were fractionated using centrifugal ultrafiltration (CFU) devices (Microsep ${ }^{\circledR}$, Pall Corporation) with $1 \mathrm{kDa}$ (MAP001C36) cutoffs to ensure the MOCs phase were completely separated. The samples in the NSW were fractionated using CFU with $1 \mathrm{kDa}$ and $3 \mathrm{kDa}$ cutoffs to separate the natural organic matter of different moleculr weight. The following is the brief introduction of the CFU operation. A total of $15 \mathrm{~mL}$ sample was loaded in a CFU unit, and then centrifuged $(4000 \times g$ ) to near dryness (or $<0.5 \mathrm{~mL}$ ), followed the details in Xu and Guo (2017). Pipetted residual solution on the ultrafiltration membrane was added into a $15 \mathrm{~mL} P \mathrm{PP}$ centrifuge tube (FCOLON ${ }^{\mathrm{TM}}$ ) and diluted to $7.5 \mathrm{~mL}$ with $2 \mathrm{~mol} / \mathrm{L}$ $\mathrm{HCl}$ to be digested for $48 \mathrm{~h}$. A total of $0.5 \mathrm{~mL}$ ultrafiltrate was transferred into a $15 \mathrm{~mL}$ PP centrifuge tube, diluted to $12.5 \mathrm{~mL}$ with $2 \mathrm{~mol} / \mathrm{L} \mathrm{HCl}$. All treated samples were stored at $4^{\circ} \mathrm{C}$ until 


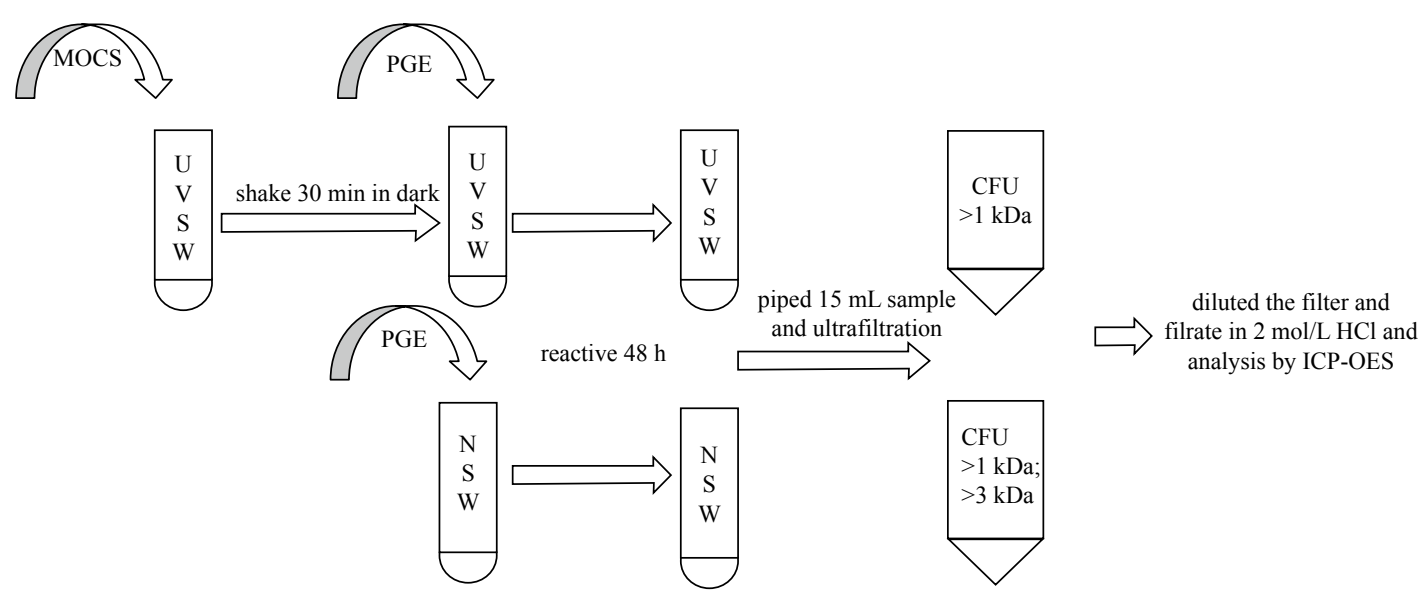

Fig. 1. Schematized chart of the adsorption procedures. UVSW represents the ultraviolet irradiated natural seawater, NSW natural seawater, and CFU centrifugal ultrafiltration device. $1 \mathrm{kDa}$ and $3 \mathrm{kDa}$ was the cutoff of the CFU in the experiment.

further analysis. The pH during the adsorption should be strictly controlled, for the excessive changes of $\mathrm{pH}$ might result in the formation of colloids, which could inferfer the adsorption significantly. Three reapeat operations were conducted simultaneouly for each adsorption process to eliminate experimental errors.

\subsection{Sample analysis and error control}

$\mathrm{Pt}, \mathrm{Pd}$ and Rh were analyzed with the inductively coupled plasma optical emission spectrometer (ICP-OES, Optima 7000, PerkinElmer $^{\circledR}$ ). To minimize the saline interference, the filtrates were diluted 25 -fold in $2 \mathrm{~mol} / \mathrm{L} \mathrm{HCl}$ to maintain the dissolved salt $<0.1 \%(\mathrm{w} / \mathrm{v})$. The instrument was calibrated using multi-element standards prepared in UVSW that was acidified and diluted with $2 \mathrm{~mol} / \mathrm{L} \mathrm{HCl}$. The concentrations of Pt, Pd and Rh were determined by the spectral signals at 265.95, 363.47 and $343.49 \mathrm{~nm}$, respectively. The drift of the standard curve caused by the operation of the instrument was eliminated by the correction of the curves every 30 samples. The possible interference mainly came from the adsorption of PGE ions on the vessel wall. Therefore, the flasks were filled with $2 \mathrm{~mol} / \mathrm{L} \mathrm{HCl}$ after the adsorption experiments and digestd for about $48 \mathrm{~h}$, and then the concentrations of PGEs in the solutions were determined.

\subsection{Partition coefficient}

The partition coefficient $\left(K_{\mathrm{d}}\right)$ of PGEs between the dissolved phase and colloidal phase was calculated by a traditional formula expressed as the following form (Honeyman and Santschi, 1989; Yang et al., 2013):

$$
K_{\mathrm{d}}=\frac{C_{\mathrm{fa}}}{C_{\mathrm{ft}} C_{\mathrm{T}}},
$$

where $C_{\mathrm{fa}}$ is the concentrations of PGEs in the colloidal phase; $C_{\mathrm{ft}}$ is the concentrations of PGEs in the dissolved phase; $C_{\mathrm{T}}$ is the total concentration of MOCs or DOC in the samples. Hereafter, the $K_{\mathrm{d}}$ values are reported in the form of $\log _{10} K_{\mathrm{d}}($ in L/g).

\section{Results and discussion}

\subsection{The mass balances of PGEs}

In view of the precipitation of PGEs, adsorption of the vessel wall, and other interferences during the experiments, the total recoveries (consisting of the concentrations of PGEs in the CFU filtrates $\left(C_{\mathrm{fa}}\right)$ and cutoffs $\left(C_{\mathrm{ft}}\right)$ and the loss in the adsorptoion experiments $\left.\left(C_{\mathrm{p}}\right)\right)$ of $\mathrm{Pt}, \mathrm{Pd}$ and $\mathrm{Rh}$ were investigated. The average recoveries of PGEs in the adsorption experiments in UVSW and NSW ranged from $75.8 \%$ to $111.8 \%$. The loss increased with the order $\mathrm{Pt}>\mathrm{Rh}>\mathrm{Pd}$. For Pt, the average recovery was $99.3 \%$; for $\mathrm{Pd}$, the average recovery was $82.8 \%$, with the highest loss being about $17.2 \%$; the average loss of Rh was about $10 \%$.

It could be concluded that the precipitation was the main factor to cause the loss of PGEs during the experiments, because there was no obvious adsorption onto the vessel wall $(<0.1 \%)$. Moreover, the precipitation loss of PGEs varied with the types of MOCs and the CFU cutoffs (Fig. 2). For Pt, the total recovery was higher than those of $\mathrm{Pd}$ and $\mathrm{Rh}$, and the precipitation loss was less than 3\% (Fig. 2a). Nevertheless, the loss of Pd showed another characteristic. In the presence of HA and APS, a significant loss of Pd occurred (about 20\%), but its loss was less than $3 \%$ in the presence of BSA. No obvious Pd loss occurred in the $>1 \mathrm{kDa}$ fraction of NDOM, and about $20 \%$ loss occurred in the $>3 \mathrm{kDa}$ fraction (Fig. 2b). For Rh, the slightest loss $(<1 \%)$ occurred in the presence of APS but the loss increased to about $9.1 \%$ in the presence of HA. In the presence of BSA, the obvious loss was only found at $48 \mathrm{~h}$ (about $17.6 \%$ ) and no remarkable changes occurred at other time. In the NDOM experiments, the loss of Rh increased with time in the $>1 \mathrm{kDa}$ fraction but decreased in the $>3$ $\mathrm{kDa}$ fraction (Fig. 2c).

The loss characteristics of PGEs showed that the constituents of NDOM could influence the migration of PGEs in seawater. Compared to Pd and Rh, the slight loss of Pt indicated that the complexes formed by this element and organic matter was more soluble in seawater (Wood et al., 1994; Takahashi et al., 1999; Sures and Zimmermann, 2007; Cobelo-García et al., 2008). The migration of Pd could be deeply influenced by BSA and HA because Pd precipitates easily with these two MOCs in seawater (Turner et al., 2006; Sures and Zimmermann, 2007). Moreover, the higher loss of $\mathrm{Pd}$ in the $>3 \mathrm{kDa}$ fraction showed that the organic matter with higher molecular weight might dominate the precipitation behavior of Pd-NDOM complexes in seawater. It was easy for $\mathrm{Rh}$ to form precipitates at the $\mathrm{pH}$ used in this research (Colombo et al., 2008; Cobelo-García, 2013). However, the higher total recoveries of this element in the presence of BSA and 

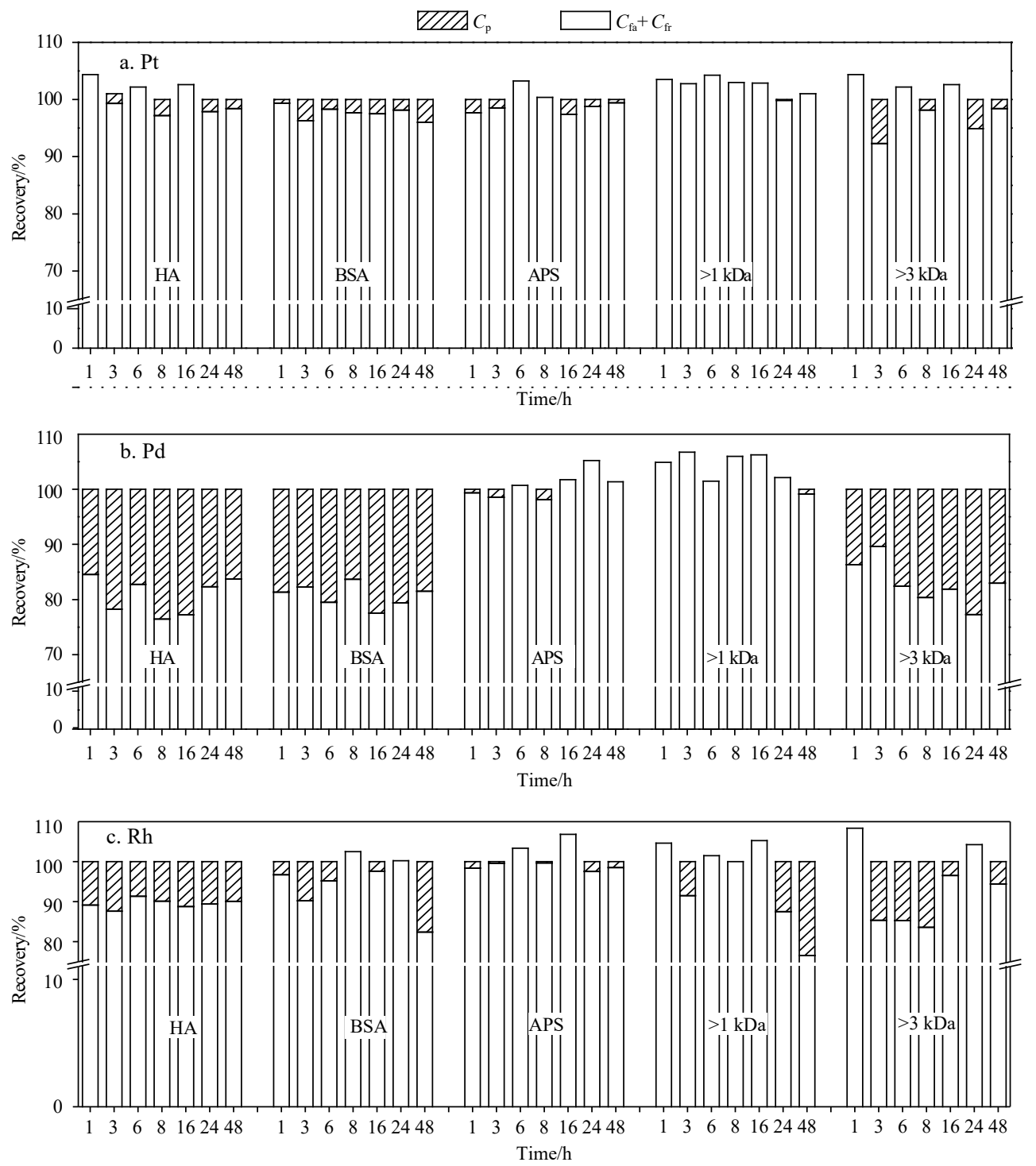

Fig. 2. Compositions of the total mass recovery of PGEs on different type of MOCs and different molecular weight fraction of NDOM. $C_{\mathrm{fa}}$ represents the concentrations of PGEs in filtrates, $C_{\mathrm{fr}}$ the concentrations of PGEs in filter, $C_{\mathrm{p}}$ the loss of PGEs in the partition experiment, HA humic acid, APS carrageenan, and BSA bovine serum albumin.

APS indicated that the complexes they formed were more soluble than Rh-HA. The change of Rh loss in different fractions of NDOM indicated that the amount of 1-3 kDa constituents might a dominating factor to influence the migration of $\mathrm{Rh}$.

\subsection{Adsorption behaviors of PGEs on MOCs in UVSW}

The behaviors of Pt, Pd and Rh distributing between the colloidal phase and dissolved phase varied and changed significantly with time (Fig. 3). For a given element of PGEs, the fractionation changed with the type of MOCs; but for a given type of MOCs, the fractionation tended to have the same situation.

The kinetic curves of Pt, Pd and Rh interacting with HA could be divided into two stages, the first $8 \mathrm{~h}$ and the remaining $40 \mathrm{~h}$ (Fig. 3a). In the first $8 \mathrm{~h}$, the adsorption and the $\log _{10} K_{\mathrm{d}}$ increased with time (Figs $3 \mathrm{a}$ and 4 ). The maximum adsorption appeared at $8 \mathrm{~h}$; with the experiment entering the second stage (8-48 h), PGE ions started to desorb from HA (Fig. 4). The trend of $\log _{10} K_{\mathrm{d}}$ with time was consistent with changes of the adsorption (Figs $3 a$ and 4). The adsorption of Pd onto HA reached equilibrium because the $\log _{10} K_{\mathrm{d}}$ did not change after $24 \mathrm{~h}$ (Fig. 4). However, the interactions between Pt and HA and Rh and HA were still active. This phenomenon may be related to the formation of the PGE-HA complexes (Cook and Fletcher, 1993). The interactions between $\mathrm{Pd}$ and HA were faster than that of $\mathrm{Pt}$ in the aquatic environment and formed stable Pd-humate complexes (Wood et al., 1994). However, for $\mathrm{Pt}$, the interactions were slow and it was impossible to determine whether the Pt-HA complexes existe (Wood, 1996). Moreover, the interactions between Rh and HA may be more complicated, because there could be some unstable Rh-HA complexes appearing during the experiments (Cobelo-García, 2013). The difference in the adsorption quantity $(\mathrm{Pd} \approx \mathrm{Rh}>\mathrm{Pt})$ may be the result of the $\mathrm{Cl}^{-}$presence in seawater (Takahashi et al., 1999; Byrne and Yao, 2000). Pd and Rh tended to form complexes with HA, but Pt tended to bind with chloride ions (Takahashi et al., 1999). Hence, $\mathrm{Cl}^{-}$could enhance the solubility of $\mathrm{Pt}$ in seawater (Colombo et al., 2008).

For BSA, the kinetic curves were similar to those of HA, but a slight difference was observed in the desorption stage (Fig. 3b). 

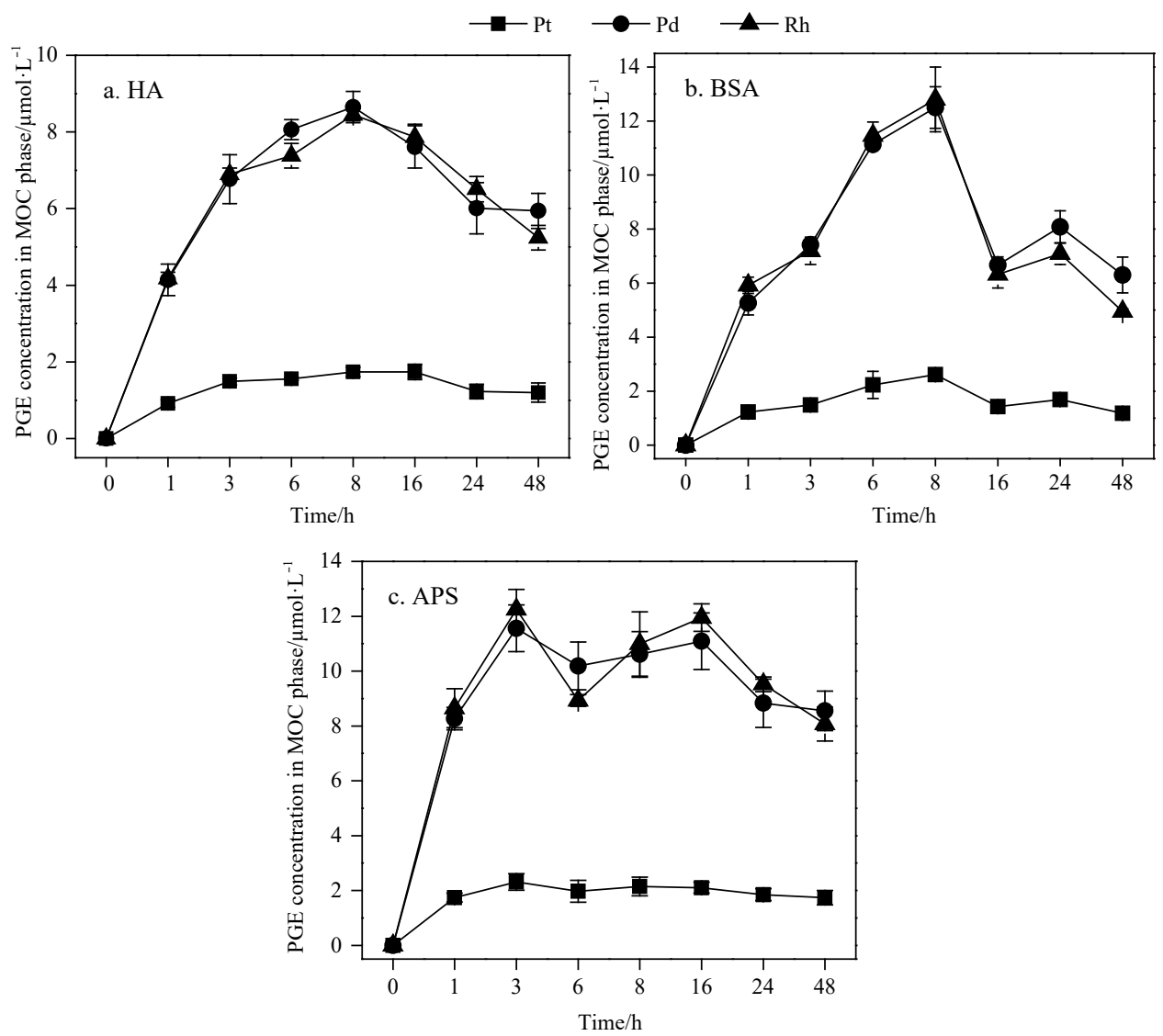

Fig. 3. Kinetics of Pt, Pd and Rh partitioning on different types of the MOCs. HA represents humic acid, APS carrageenan, and BSA bovine serum albumin. The cutoff of CFU used in MOCs experiment was $1 \mathrm{kDa}$.

The $8 \mathrm{~h}$ was still the demarcation point of the adsorption experiments (Figs $3 \mathrm{~b}$ and 4). However, none of the given elements reached adsorption equilibrium within $48 \mathrm{~h}$ and the desorption process became more complicated. A rapid desorption stage was found at 8-16 h, whereas a slight adsorption stage occurred again between 16 to $24 \mathrm{~h}$, and then desorption continued after $24 \mathrm{~h}$ (Figs 3 and 4). This complicated process may be the result of the interactions between PGE ions and the colloids formed by BSA. It was known that Pt, Pd and Rh should form some stable complexes with the S- or N-donors of the proteins (Wood et al., 1996). But under the conditions of this research, the zeta potential of BSA was around $-10 \mathrm{mV}$, the colloids formed by BSA were not stable and the dispersion layer surface gathered a large number of hydroxyl groups (Xu et al., 2003; Ye et al., 2007; Jin et al., 2013; Liu et al., 2014). Hence, the lager number of the O-donor would compete with the $\mathrm{S}$ - or $\mathrm{N}$-donors in adsorbing the PGE ions in seawater, resulting in the complicated adsorption behavior.

The adsorption of PGEs on APS was different from the other two model organic compounds, with the maximum adsorption point disappearing and the kinetic curves being smooth (Fig. 3c). The adsorption process could be divided into three stages, the rapid adsorption stage, the maximum adsorption stage and the desorption stage (Figs 3 and 4). The rapid adsorption stage ended at $3 \mathrm{~h}$, and the maximum adsorption stage lasted nearly $13 \mathrm{~h}$ with the fluctuations less than $4 \%$. The desorption stage occured after $16 \mathrm{~h}$, and the desorption magnitude was less than that in the experiments with BSA. The kinetic process did not achieve equilibrium by the end the experiments because the $\log _{10} K_{\mathrm{d}}$ was still decreasing. This kinetic behavior may be related to the structure and dispersion of carrageenan in seawater. Unlike HA as a mixture and BSA containing multiple amino acid residues, carrageenan possesses a stable structure. Hence, the complexes between PGEs and APS might be simple. In addition, carrageenan tends to form a colloidal system with network structures in saline solutions (Langendorff et al., 2000; Guo et al., 2009; Lundin et al., 2000), which could result in the complicated adsorption process. The adsorption of PGEs on APS did not reach equilibrium within $48 \mathrm{~h}$ and this could be related to the change of the colloidal structure formed by APS (Fig. 4), but more proofs are needed to better explain this phenomenon.

\subsection{Adsorption behaviors of PGEs on NDOM in NSW}

Unlike the model organic matter, the composition and molecular weight of natural organic matter is unclear. But with the ultrafiltration, the constituents in different molecular weights of NDOM could be separated effectively ( $\mathrm{Xu}$ and Guo, 2017). The adsorption of PGEs on the two fractions of NDOM, i.e., the > $1 \mathrm{kDa}$ fraction and the $>3 \mathrm{kDa}$ fraction, was investigated to explore the roles of the NDOM constituents in this study.

In the experiments with the $>1 \mathrm{kDa}$ NDOM fraction, the kinetic curves showed two stages, adsorption and desorption (Fig. 5), but the $\log _{10} K_{\mathrm{d}}$ showed another trend. For Pd and Pt (Fig. 4), a similar kinetic curve was observed, but the change of $\log _{10} K_{\mathrm{d}}$ was different. The partition coefficient of Pt fluctuated slightly in the experiments with the $>1 \mathrm{kDa}$ fraction, about 1.30-1.59. But for Pd, an obvious decrease of $\log _{10} K_{\mathrm{d}}$ occurred in $0-24 \mathrm{~h}$. For Rh in the experiments with the $>1 \mathrm{kDa}$ fraction, a stable adsorption process was found before $18 \mathrm{~h}$ and it changed to the desorption stage 

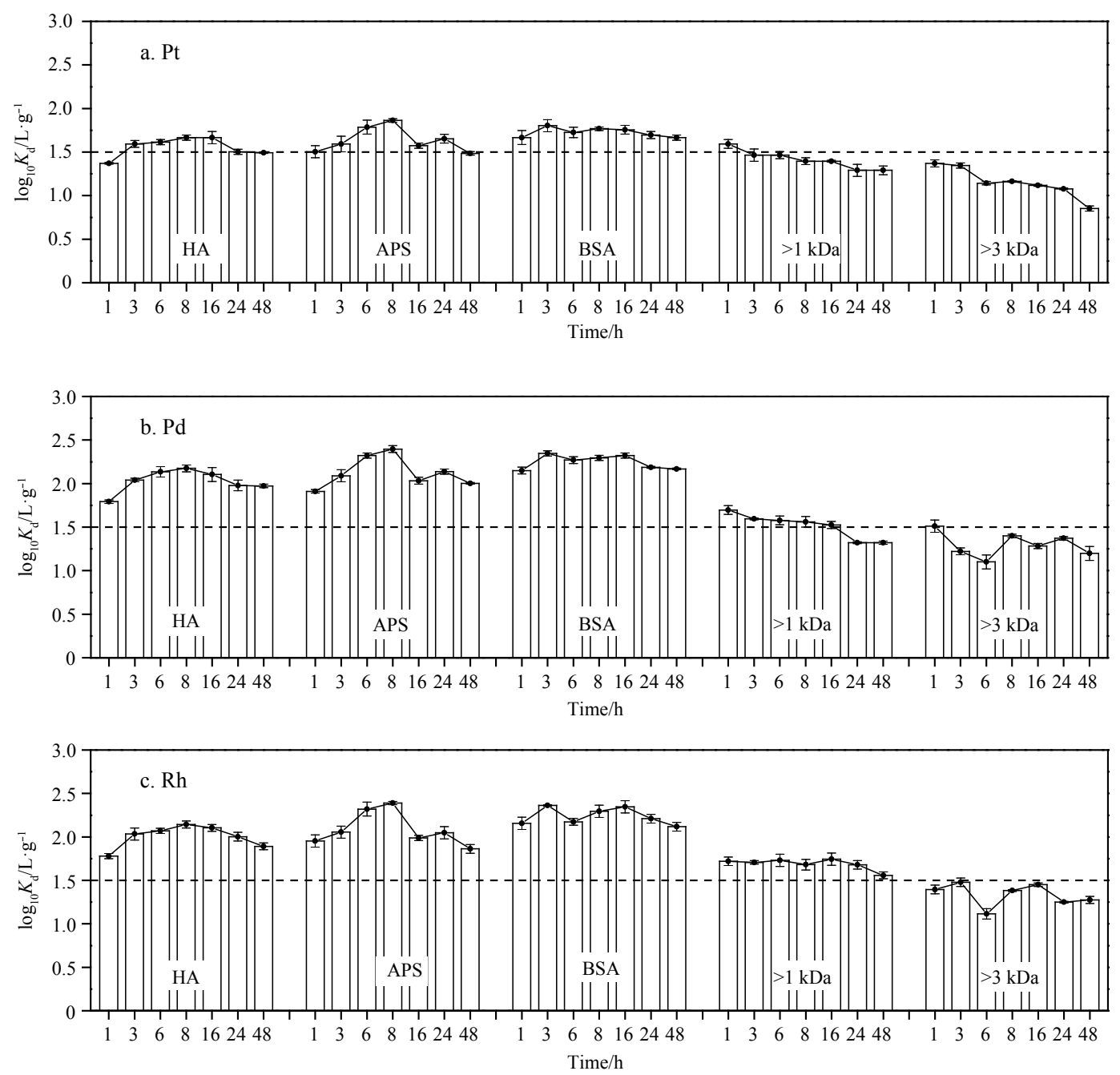

Fig. 4. Partition coefficients of PGEs on different types of MOCs and different molecular weight fraction of NDOM. HA represents humic acid, APS carrageenan, and BSA bovine serum albumin. $>1 \mathrm{kDa}$ means the fraction of $>1 \mathrm{kDa}$ of NOM, and $>3 \mathrm{kDa}$ the fraction of $>3 \mathrm{kDa}$ of NOM.
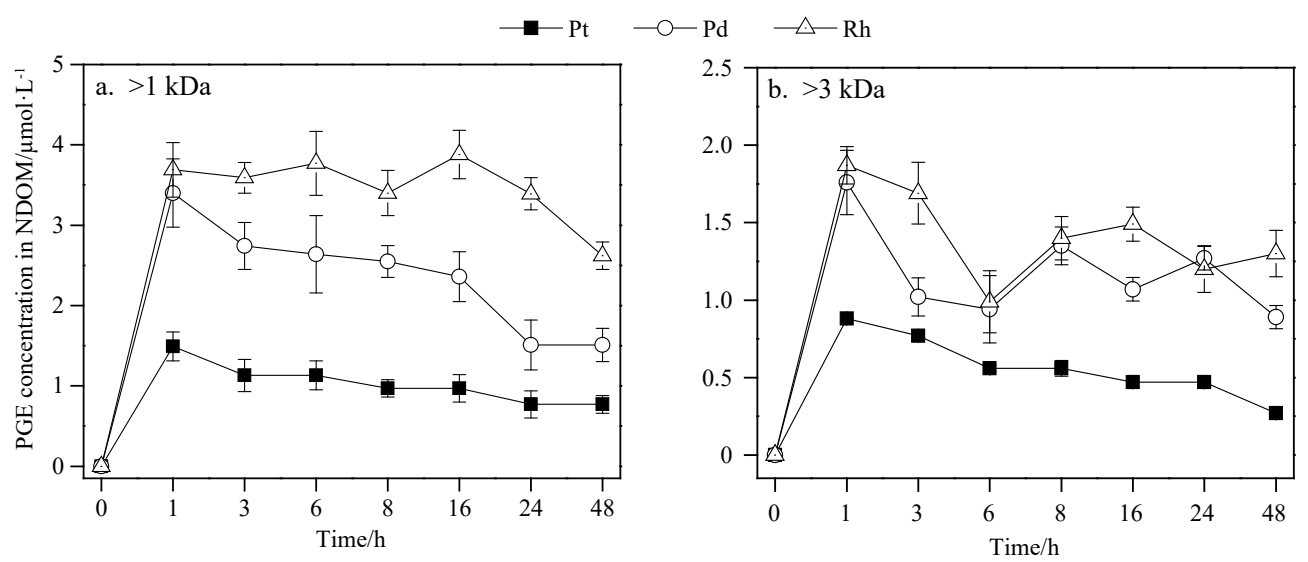

Fig. 5. Kinetics of PGE partitioning on different molecular weight fraction of NDOM.

by then (Fig. 4). The interaction of PEGs with the $>1 \mathrm{kDa}$ NDOM fraction reached equilibrium around $24 \mathrm{~h}$ for Pt but achieved no equilibrium for Pd and Rh (Fig. 4). During the whole kinetic process, the adsorption of Rh was obviously higher than other elements in the experiments with the $>1 \mathrm{kDa}$ fraction, and the ad- sorption of Pd was slightly higher than that of Pt (Fig. 5). But for the change of $\log _{10} K_{\mathrm{d}}$, the partition ability of Rh was the weakest and Pt was the highest (Fig. 4). This phenomenon might be owing to the loss of $\mathrm{Rh}$ in the experiments with the $>1 \mathrm{kDa}$ fraction, in which the precipitation removed more $\mathrm{Rh}$ from dissolved 
phase (Fig. 2). Another possible factor might be related to the compound composition of the NDOM used in this study. But more evidence is needed in the future because the separation and identification of the compounds of NDOM are difficult.

In the experiments with the $>3 \mathrm{kDa}$ NDOM fraction, the kinetic curves were smooth and with little change (Fig. 5). A rapid adsorption process occurred in $1 \mathrm{~h}$ and the quantity of PGEs that interacted with the $>3 \mathrm{kDa}$ fraction was smaller than with the $>1 \mathrm{kDa}$ fraction (Figs 4 and 5). However, like the partition in the experiments with the $>1 \mathrm{kDa}$ fraction, the $\log _{10} K_{\mathrm{d}}$ showed another trend. Based on the kinetic curves, no obvious desorption of $\mathrm{Pt}$ and Pd occurred, and Rh only showed slight desorption (Fig. 5). But for the $\log _{10} K_{\mathrm{d}}$, an obvious decrease was observed (Fig. 4). However, the kinetic curve showed that there were no obvious fluctuations with time during the dsorption. Hence, the loss of PGEs in the colloidal phase could be caused by the precipitation (Fig. 2). A portion of PGE ions complexing with organic matter precipitated to the bottom of the solution which resulted in the decrease in the total colloidal phase but no obvious influence on the dissolved phase. Therefore, the migration of PGEs between dissoved and colloidal phases in seawater was likely dominated by the organic constituents with molecular weight of $<3 \mathrm{kDa}$.

For all the cases, it could be found that the adsorption of PGEs on NDOM was closely related to the composition of NDOM and the precipitation of the PGE-NDOM complexes. The partition coefficient of $\mathrm{Pt}$ in the experiments with the $>1 \mathrm{kDa}$ fraction was higher than that with the $>3 \mathrm{kDa}$ fraction. It was reported that Pt responded slightly to the change of molecular weight of NDOM and the migration behavior was probably mainly dominated by its ions themselves (Colombo et al., 2008). The adsorption of Pd also had similar behavior with Pt which showed that NDOM with with molecular weight of 1-3 kDa had a great influence on the partition of these two elements. Rh had higher adsorption in the experiments with the $>1 \mathrm{kDa}$ fraction than that with the $>3 \mathrm{kDa}$ fraction but their $\log _{10} K_{\mathrm{d}}$ values were similar, which showed that Rh might be combined with some specific organic constituents. The different trend of $\log _{10} K_{\mathrm{d}}$ and kinetic curves of PGEs interacting with NDOM indicated siginificant influence of precipitation on the migration of PGEs in seawater. However, owing to the limitations in physical and chemical separation, there is insufficient information in this subject. Hence, further research is needed to get the information about the impact of NDOM on the fractionation of PGEs in seawater.

\subsection{Implications for $P t, P d$ and $R$ h reactivity in seawater}

As discussed in Sections 3.1-3.3, the fractionations of Pt, Pd and $\mathrm{Rh}$ in seawater were significantly influenced by NDOM. Based on the trend of $\log _{10} K_{\mathrm{d}}$, changes of precipitation with time and kinetic curves (Figs 2-5), it could be inferred that there was a possible migration of PGEs between the colloidal phase and the dissolved phase in seawater. When the PGE ions met the colloidal organic matter in seawater, a portion of ions adsorbed on the surface of colloids or entered the interior of the colloids, and a portion of them precipitated to the bottom of the solution owing to flocculation. These behaviors were related to the constituents of NDOM. In natural seawater, Pd had light extent of precipitation in the experiments with the $>1 \mathrm{kDa}$ fraction and larger precipitation loss occurred in the experiments with the $>3 \mathrm{kDa}$ fraction (Fig. 2). This suggests that Pd may form some insoluble matter with the $>3 \mathrm{kDa}$ NDOM (Sures and Zimmermann, 2007; Zimmermann et al., 2017). However, the organic substances that easily precipitates with Pd were humic- and protein-like constituents, and as much as $90 \%$ of which were reported to be found in the $<3 \mathrm{kDa}$ fraction (Xu and Guo, 2017). Hence, the complexes formed by Pd and the 1-3 kDa NDOM were unstable and prone to coagulation. Moreover, the precipitation of $\mathrm{Pd}$ in the $>3 \mathrm{kDa}$ fraction might be caused by the higher molecular weight of NDOM. The behaviors of Pt were similar to Pd, but the lighter precipitation extent of Pt-NDOM complexes indicated that they might be more stable than other PGE-NDOM complexes. Rh had similar $\log _{10} K_{\mathrm{d}}$ and adsorption in the experiments with different NDOM fractions, and the data gained in the experiments with the $>1 \mathrm{kDa}$ fraction was more stable than those with the $>3 \mathrm{kDa}$ fraction. It indicated that $\mathrm{Rh}$ might form complexes with specific organic substances. In general, the 1-3 kDa NDOM may be the key fraction of dominating the behavior of PGEs in seawater. In addition, a large number of low molecular weight organic constituents, accounting for up to $90 \%$ of DOM (Wood, 1996; Xu and Guo, 2017), may also bind with PGE ions in the dissolved phase. Those organic complexes formed by PGE ions and lower molecular weight organic constituents are not easy to make a colloidal mixture, which makes PGE ions more soluble in seawater. Comparing the $\log _{10} K_{\mathrm{d}}$ and kinetic curves of PGEs in the NDOM and MOC solutions, no similar behaviors were observed. Hence, the interaction of PGE ions with colloidal organic matter might be the result of the combination of their complexation with multiple organic constituents. However, there are few studies in this aspect and further research is needed.

\section{Conclusions}

Controlled kinetic experiments were conducted on the formation of Pt, Pd and Rh complexes with different types of MOCs and NDOM in seawater. The results showed that the tested MOCs played an important role in the scavenging of $\mathrm{Pt}, \mathrm{Pd}$ and $\mathrm{Rh}$ ions in seawater. For the NDOM experiments, only the fractionation of $\mathrm{Pt}$ in the $>1 \mathrm{kDa}$ fraction reached equilibrium around $24 \mathrm{~h}$; other adsorption experiments did not display equilibrium even the duration was extended to $48 \mathrm{~h}$. The high molecular weight organic constituents slightly influenced the absorption of Pt and Pd by colloidal phase because the $\log _{10} K_{\mathrm{d}}$ values in the tested MOCs solutions and the $>3 \mathrm{kDa}$ fraction were lower than in the $>1 \mathrm{kDa}$ fraction. More research is needed to explain the kinetic behavior of Rh because of its complicated fractionation feature. From the $\log _{10} K_{\mathrm{d}}$ and kinetic curves, it could be found that the 1-3 kDa fraction may play an important role in regulating the interaction of PGE ions and the colloidal phase of organic matter.

In sum, the compositions of NDOM were found to be crucial in regulating the migration and conversion of $\mathrm{Pt}, \mathrm{Pd}$ and $\mathrm{Rh}$ ions in seawater. However, some complicated phenomena cannot be explained clearly. Further studies are needed to quantitatively characterize the complexes of NDOM-PGEs, the partition behaviors of PGEs with different fractions of NDOM, the equilibrium time of the interaction between Rh and all the tested MOCs and NDOM fractions and the partition kinetics of PGEs in different proportions of mixed model organic compounds.

\section{Acknowledgements}

We thank Yuxi Lu and Tianci Gao from Yantai Institute of Coastal Zone Research, Chinese Academy of Sciences for their constant field and laboratory assistance, helpful advice and indepth discussion.

\section{References}

Baker A, Spencer R G M. 2004. Characterization of dissolved organic matter from source to sea using fluorescence and absorbance 
spectroscopy. Science of the Total Environment, 333(1-3): 217-232, doi: 10.1016/j.scitotenv.2004.04.013

Byrne R H, Yao Wensheng. 2000. Formation of palladium (II) hydroxychloride complexes and precipitates in sodium chloride solutions and seawater. Geochimica et Cosmochimica Acta, 64(24): 4153-4156, doi: 10.1016/S0016-7037(00)00501-9

Clément N, Muresan B, Hedde M, et al. 2015. Assessment of palladium footprint from road traffic in two highway environments. Environmental Science and Pollution Research, 22(24): 20019-20031, doi: 10.1007/s11356-015-5241-9

Cobelo-García A, Turner A, Millward G E, et al. 2007. Behaviour of palladium(II), platinum(IV), and rhodium(III) in artificial and natural waters: Influence of reactor surface and geochemistry on metal recovery. Analytica Chimica Acta, 585(2): 202-210, doi: 10.1016/j.aca.2006.12.029

Cobelo-García A, Turner A, Millward G E. 2008. Fractionation and reactivity of platinum group elements during estuarine mixing. Environmental Science \& Technology, 42(4): 1096-1011

Cobelo-García A. 2013. Kinetic effects on the interactions of Rh (III) with humic acids as determined using size-exclusion chromatography (SEC). Environmental Science and Pollution Research, 20(4): 2330-2339, doi: 10.1007/s11356-012-1113-8

Colombo C, Oates C J, Monhemius A J, et al. 2008. Complexation of platinum, palladium and rhodium with inorganic ligands in the environment. Geochemistry: Exploration, Environment, Analysis, 8(1): 91-101, doi: 10.1144/1467-7873/07-151

Cook S J, Fletcher W K. 1993. Distribution and behaviour of platinum in soils, sediments and waters of the Tulameen ultramafic complex, southern British Columbia, Canada. Journal of Geochemical Exploration, 46(3): 279-308, doi: 10.1016/0375-6742(93) 90026-I

Guéguen C, Guo Laodong, Wang Deli, et al. 2006. Chemical characteristics and origin of dissolved organic matter in the Yukon River. Biogeochemistry, 77(2): 139-155, doi: 10.1007/s10533005-0806-1

Guo Laodong, Santschi P H. 1997. Composition and cycling of colloids in marine environments. Reviews of Geophysics, 35(1): 17-40, doi: 10.1029/96RG03195

Guo Laodong, Santschi P H. 2007. Ultrafiltration and its applications to sampling and characterisation of aquatic colloids. In: Wilkinson K J, Lead J R, eds. Environmental Colloids and Particles: Behaviour, Separation and Characterisation. Wilkinson: John Wiley \& Sons, 159-221

Guo Lei, Sun Changmei, Li Guiying, et al. 2009. Thermodynamics and kinetics of Zn(II) adsorption on crosslinked starch phosphates. Journal of Hazardous Materials, 161(1): 510-515, doi: 10.1016/j. jhazmat.2008.04.003

He Wei, Chen Meilian, Schlautman M A, et al. 2016. Dynamic exchanges between DOM and POM pools in coastal and inland aquatic ecosystems: A review. Science of the Total Environment, 551-552: 415-428, doi: 10.1016/j.scitotenv.2016.02.031

Honeyman B D, Santschi P H. 1989. A Brownian-pumping model for oceanic trace metal scavenging: Evidence from Th isotopes. Journal of Marine Research, 47(4): 951-992, doi: 10.1357/ 002224089785076091

Ilina S M, Drozdova O Y, Lapitskiy S A, et al. 2014. Size fractionation and optical properties of dissolved organic matter in the continuum soil solution-bog-river and terminal Lake of a boreal watershed. Organic Geochemistry, 66: 14-24, doi: 10.1016/j. orggeochem.2013.10.008

Jin Rencheng, Xu Yanbin, Li Guihua, et al. 2013. Hierarchical chlorophytum-like Bi2S3 architectures with high electrochemical performance. International Journal of Hydrogen Energy, 38(22): 9137-9144, doi: 10.1016/j.ijhydene.2013.05.082

Koek M, Kreuzer O P, Maier W D, et al. 2010. A review of the PGM industry, deposit models and exploration practices: Implications for Australia's PGM potential. Resources Policy, 35(1): 20-35, doi: 10.1016/j.resourpol.2009.08.001

Langendorff V, Cuvelier G, Michon C, et al. 2000. Effects of carrageenan type on the behaviour of carrageenan/milk mixtures. Food Hydrocolloid, 14(4): 273-280, doi: 10.1016/S0268-005X(99)
00064-8

Lin Peng, Chen Min, Guo Laodong. 2015. Effect of natural organic matter on the adsorption and fractionation of thorium and protactinium on nanoparticles in seawater. Marine Chemistry, 173: 291-301, doi: 10.1016/j.marchem.2014.08.006

Liu Yan, Chen Mingmao, Wang Shuaihua, et al. 2014. New insight into the stereoselective interactions of quinine and quinidine, with bovine serum albumin. Journal of Molecular Recognition, 27(5): 239-249, doi: 10.1002/jmr.2355

Lundin L, Odic K, Foster T J, et al. 2000. Phase separation in mixed carrageenan systems. In: Lal M, Lillford P J, Naik V M, et al., eds. Supramolecular and Colloidal Structures in Biomaterials and Biosubstrates. Singapore: World Scientific, 436-449

Mitra A, Sen I S. 2017. Anthrobiogeochemical platinum, palladium and rhodium cycles of earth: Emerging environmental contamination. Geochimica et Cosmochimica Acta, 216: 417-432, doi: 10.1016/j.gca.2017.08.025

Mudd G M. 2012. Key trends in the resource sustainability of platinum group elements. Ore Geology Reviews, 46: 106-117, doi: 10.1016/j.oregeorev.2012.02.005

Para J, Coble P G, Charrière B, et al. 2010. Fluorescence and absorption properties of chromophoric dissolved organic matter (CDOM) in coastal surface waters of the northwestern Mediterranean Sea, influence of the Rhone River. Biogeosciences, 7(12): 4083-4103, doi: 10.5194/bg-7-4083-2010

Pawlak J, Łodyga-Chrušcińska E, Chrustowicz J. 2014. Fate of platinum metals in the environment. Journal of Trace Elements in Medicine and Biology, 28(3): 247-254, doi: 10.1016/j.jtemb. 2014.03.005

Ravindra K, Bencs L, Van Grieken R. 2004. Platinum group elements in the environment and their health risk. Science of the Total Environment, 318(1-3): 1-43, doi: 10.1016/S0048-9697(03) 00372-3

Reith F, Campbell S G, Ball A S, et al. 2014. Platinum in Earth surface environments. Earth-Science Reviews, 131: 1-21, doi: 10.1016/j. earscirev.2014.01.003

Ruchter N, Sures B. 2015. Distribution of platinum and other traffic related metals in sediments and clams (Corbicula sp.). Water Research, 70: 313-324, doi: 10.1016/j.watres.2014.12.011

Sørensen S N, Engelbrekt C, Lützhøft H C H, et al. 2016. A multimethod approach for investigating algal toxicity of platinum nanoparticles. Environmental Science \& Technology, 50(19): 10635-10643

Suchá V, Mihaljevič M, Ettler V, et al. 2016. The pH-dependent release of platinum group elements (PGEs) from gasoline and diesel fuel catalysts: Implication for weathering in soils. Journal of Environmental Management, 171: 52-59

Sures B, Zimmermann S. 2007. Impact of humic substances on the aqueous solubility, uptake and bioaccumulation of platinum, palladium and rhodium in exposure studies with Dreissena polymorpha. Environmental Pollution, 146(2): 444-451, doi: 10.1016/j.envpol.2006.07.004

Takahashi Y, Minai Y, Ambe S, et al. 1999. Comparison of adsorption behavior of multiple inorganic ions on kaolinite and silica in the presence of humic acid using the multitracer technique. Geochimica et Cosmochimica Acta, 63(6): 815-836, doi: 10.1016/S0016-7037(99)00065-4

Turner A, Crussell M, Millward G E, et al. 2006. Adsorption kinetics of platinum group elements in river water. Environmental Science \& Technology, 40(5): 1524-1531

Verdugo P, Alldredge A L, Azam F, et al. 2004. The oceanic gel phase: a bridge in the DOM-POM continuum. Marine Chemistry, 92(1-4): 67-85, doi: 10.1016/j.marchem.2004.06.017

Wiseman C L S, Zereini F. 2009. Airborne particulate matter, platinum group elements and human health: A review of recent evidence. Science of the Total Environment, 407(8): 2493-2500, doi: 10.1016/j.scitotenv.2008.12.057

Wood S A. 1996. The role of humic substances in the transport and fixation of metals of economic interest $(\mathrm{Au}, \mathrm{Pt}, \mathrm{Pd}, \mathrm{U}, \mathrm{V})$. Ore Geology Reviews, 11(1-3): 1-31, doi: 10.1016/0169-1368(95) 00013-5 
Wood S A, Tait C D, Vlassopoulos D, et al. 1994. Solubility and spectroscopic studies of the interaction of Palladium with simple carboxylic acids and fulvic acid at low temperature. Geochimica et Cosmochimica Acta, 58(2): 625-637, doi: 10.1016/00167037(94)90493-6

$\mathrm{Xu}$ Tongwen, Fu Rongqiang, Yan Lifeng. 2003. A new insight into the adsorption of bovine serum albumin onto porous polyethylene membrane by zeta potential measurements, FTIR analyses, and AFM observations. Journal of Colloid and Interface Science, 262(2): 342-350, doi: 10.1016/S0021-9797(03)00208-X

$\mathrm{Xu}$ Huacheng, Guo Laodong. 2017. Molecular size-dependent abundance and composition of dissolved organic matter in river, lake and sea waters. Water Research, 117: 115-126, doi: 10.1016/j.watres.2017.04.006
Yang Weifeng, Guo Laodong, Chuang C Y, et al. 2013. Adsorption characteristics of ${ }^{210} \mathrm{~Pb},{ }^{210} \mathrm{Po}$ and ${ }^{7} \mathrm{Be}$ onto micro-particle surfaces and the effects of macromolecular organic compounds. Geochimica et Cosmochimica Acta, 107: 47-64, doi: 10.1016/j. gca.2012.12.039

Ye Jinfu, Lin Dongqiang, Yao Shanjing. 2007. Zeta potential of bovine serum albumin and its correlation to retention factor of ion exchange chromatography. Journal of Chemical Engineering of Chinese Universities (in Chinese), 21(3): 381-385

Zimmermann S, Wolff C, Sures B. 2017. Toxicity of platinum, palladium and rhodium to Daphnia magna in single and binary metal exposure experiments. Environmental Pollution, 224: 368-376, doi: 10.1016/j.envpol.2017.02.016 